\title{
Sustainable Business Practices and Corporate Social Responsibility in 5- Star Hotels of National Capital Region in India
}

\author{
Dr. Rekha Maitra* \\ Associate Professor-Hotel Management, Faculty of Management Studies, Manav Rachna International Institute \\ of Research and Studies, India
}

*Corresponding Author: Dr. Rekha Maitra, Associate Professor-Hotel Management, Faculty of Management Studies, Manav Rachna International Institute of Research and Studies, India

\begin{abstract}
Corporate Social Responsibility (CSR) is a popular subject of research for the researchers and scholars across the globe. Several types of research have been conducted in past to understand the concept, evolution, motives and benefits of Corporate Social Responsibility in the global, as well as in the Indian context. Corporate Social Responsibility involves "achieving commercial success in ways that honour ethical values and respect people, communities, and the natural environment" (Clark, 2006; Porter \& Kramer, 2006).

The recent development of mandatory CSR clause has engrossed the attention of corporate, ancillary units and other researchers. As per Companies Bill, 2012, Indian government mandates at least two per cent of average net profit of corporate entities for Corporate Social Responsibility (CSR) activities. This new law has brought the paradigm shift to the way CSR is being dealt with by the hospitality players. The aim of the author is to explore the CSR practices adopted in 5-star hotels of NCR and also identify the main areas of contribution, advantages and challenges involved. It will also examine the significance of eco-friendly sustainable business practices followed by 5-star hotels of NCR. The aim is to be actively committed towards the sustainability of environment through effective and eco-friendly practices.
\end{abstract}

Keywords: Triple bottom line, Sustainability, 3R, Water consumption, Energy conservation, Rain water harvesting, LEED, Green hotels

\section{INTRODUCTION}

Corporate Social Responsibility (CSR) has been in trend in the corporate arena for considerable time. Companies are thinking beyond the sole objective of profit-maximization and becoming increasingly aware of the social aspects of the business. Much of this transformation in the business mindset is also an outcome of the economic benefits of CSR in the form of improved goodwill and long-lasting customer relations. (D.Crowther, 2008).However, (Henriques, 2003) give credence to CSR, as it is proving to be more essential for preserving success in business, not only by rendering a corporate theme around which the company can unite but also by adding meaning and direction to their day-today routine operations. The need for sustainable planning and management is an important aspect of corporate social responsibility. Be it the cleanliness drive, sanitation drive or the plantation drive the awareness about the environment among the people have increased to reduce the carbon footprint. After all, in India the democracy is led by the people for the people.

Of late, the organizations and people have realized the significance of CSR. "Organizational commitment to CSR has become an important issue for prospective employees, and a good CSR track record may be necessary to recruit top level candidates (Cotterill, 2007). People prefer working for companies that care. People in organizations also seem to enjoy community service, so meeting planners are now incorporating CSR activities at meetings where participants can work together on charitable activities in the community (Scofidio, 2007)" (Lymn, 2009)

In this regard, WBCSD (World business council for sustainable council) represented "Corporate Social Responsibility is the continuing commitment by business to contribute to economic development while improving the quality of life of the workforce and their families as well as of the community and society at large". (CSR: Meeting changing expectations, p. 3) 
If hospitality organizations adopt and integrate CSR into their organizational strategies, they can facilitate innovativeness, increase their organizational competitiveness and at the same time contribute to the solution of societal problems. "Corporate Social Responsibility (CSR) has a positive relationship with businesses performance especially with service companies like Hotels, Hospitals, and Universities. The growing concentration to Corporate Social Responsibility is based on its capability to authority company performance".(Qeed, 2015).

Corporate Companies need to adopt CSR in their company polices in order to respect people, community and natural environment. As per business for social responsibility, 2003 "Corporate social responsibility is achieving commercial success in ways that honour ethical values and respect people, communities and the natural environment through which company can be benefitted in various forms causing less harm to environment, providing healthy and clean environment not only to employees but also to the society". (Rajiv Kumar, 2014)

\section{OBJECTIVES}

- To explore and compare the CSR practices adopted by 5-star hotels in National Capital Region.

- To analyze the CSR concept from the employee's perspectives and identify the reasons for the 5 -star hotels to engage in eco-friendly practices.

- To judge the hotel employee's awareness towards the significance of corporate social responsibility.

- To recommend strategies for further improvement in the adoption of CSR initiatives based on the perspectives of the employees.

The purpose of this paper is to determine the level of social responsible behaviour of the 5-star hotels in National Capital Region of India. India's hotel industry is on the elevated development path. It is vital for the hotel industry to understand and outline their efforts at CSR as part of their strategies. There is a greater need for the hotel sector to incorporate CSR in its day to day activities due to their commercial requirements. Be it the hotel laundry or the food and beverage set up, hotel industry consumes i.e. water consumption, its conservation etc. With reference to water consumption by hotels (Singh, 2015) found that the collective water consumption at Delhi's luxury hotels was 15 million litres a day.

In the given situation, "It is mandatory for the hotels to follow Ministry of tourism guidelines which states that Eco-friendly Practices i.e. sewage treatment plant, rain water harvesting, waste management, pollution control method for air, water, light and introduction of non CFC equipment for refrigeration and air conditioning, energy/water conservation (use of CFL lamps, solar energy, water saving devices/taps)" (GOI, 2014).

This research paper has addressed the level of CSR activity being carried out in hotels across the India with a focus on National Capital Region (NCR) in particular. Through a review of the literature, the paper begins by looking at the concept of CSR followed by 5 -star hotels in National Capital Region. This is followed by how the hotel employees in NCR have understood its significance and contributed in incorporating corporate social responsibility into their operations.

\section{RESEARCH METHODOLOGY}

The aim of the research paper is to be actively committed towards the sustainability of environment through effective and eco-friendly practices. To attain the aim, the task was divided into 4 phases:

- Phase one: An online questionnaire link was created and sent to hotels.

- Phase two: The hotel employees were selected as the target group and were asked to reply to the online link.

- Phase three: The responses were gathered and analysed using MS-Excel

- Phase four: The responses of the respondents are compiled and represented in the research paper. 
The current research is conducted using quantitative analysis among 31 employees from the selected 5 -star hotel properties of National Capital Region. For analysis, interviews were conducted using a semi-structured questionnaire. The research study was confined to 5 luxury hotels of NCR namely Dusit Deverana, Radisson Blu, Greater Noida ,Eros Hotel, New Delhi, The Oberoi, Gurugram, JW Marriott, New Delhi.

\section{BACKGROUND OF THE RESEARCH}

- In broad-spectrum, Corporate Social Responsibility in any organization focuses on infrastructure, water consumption, its conservation, water source, waste water management, adopted air pollution control measures, solid waste generation, energy consumption, conservation, adoption of renewable energy sources, development of environmental management group and corporate social responsibility steps.

- There are three dimensions of dealing with Corporate Social Responsibility i.e. Employees, Community and the Environment. If the employees are dedicated towards the development of community then the awareness among community may lead to a better upkeep of the environment. Most of the environment awareness programmes are organized around earth day and world environment day. If the exercise of sensitizing the people is worked upon throughout the year then we can preserve our environment in an improved manner. Mankind must realize the significance of sustainability therefore, it is necessary to plan and manage long term resources wisely and to consume them within limits.

Classification of social responsibility is represented with graphical representation.

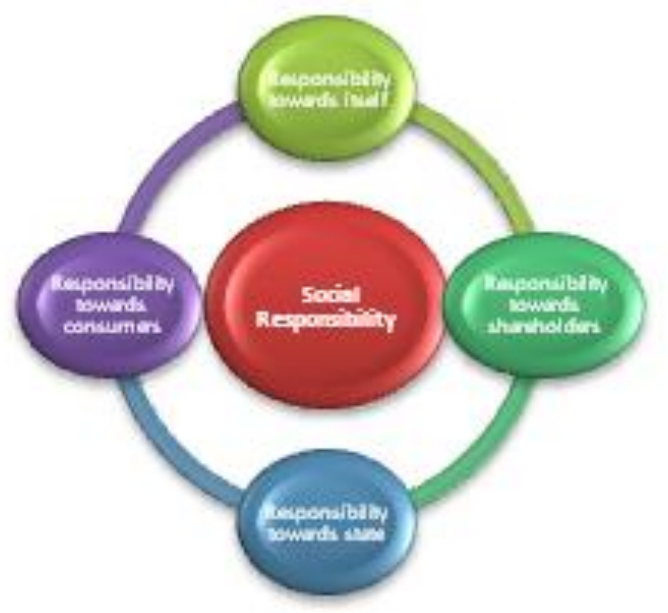

Figure1. Classification of Social Responsibility

- Corporate Social Responsibility is classified in four segments i.e.

$>$ Responsibility towards itself: Each organization has to work through the growth, expansion, and stability towards themselves. The organization has to provide the safe working environment to their employees. Organizations can train the employees for paying attention to their health and can employ differently able persons. For ex. Marriott Opens 'Hotel School' To Teach Persons with Disabilities Valuable Job Skills in December, 2015 (Tenhundfeld, 2015)

$>$ Responsibility towards stakeholders: Secure and safeguard environment inculcate a sense of responsibility among the stakeholders. Business organizations can also invest in infrastructure and activities to ensure the empowerment of women. CSR can encompass a variety of campaigns i.e. from giving away a portion of a company's proceeds to charity, to implementing "greener" business operations. Hotels can provide low-cost housing to the poor.

$>$ Responsibility towards state: It is the foremost duty of hotels to not indulge in tax evasion practice to appreciate welfare state concept. Social responsibility decisions must not be taken behind the doors and the donations must follow the proper sequence. Proper utilization of power to improve the world can bring people of all backgrounds, ages, and interests together. 
$>$ Responsibility towards consumers: It is essential for the corporations to fulfil its cultural obligations to its customers. Hotels teach the employees to be respectful to their guest. Hotel employees are the ambassadors of their guest to the organization not ambassadors of the company to their guests, which offers stupefying results.

Hotels work on individual projects which are developed, tracked and monitored towards the society in form of social, ethical and environmental progress. Hotels make a determined effort towards biodiversity conservation and habitat protection. Their vision is to be committed to maintaining a greener and healthier environment. Maximization of social welfare should be the legitimate goal of hotels due to their involvement in commercial activities, as it leaves behind the maximum carbon footprint. In this regard (Singh, 2015)confirmed that "the electricity consumed by one hotel is roughly the requirement of 600 households". For laundry operations hotel utilizes 25 gallons (94.6 litres) of water.

\section{LITERATURE REVIEW}

CSR and sustainable business practices followed by 5 star hotels of NCR are as follows:

- Shangri-La Hotels and Resorts have unified all initiatives within five key areas of CSR namely, environment, health \& safety, employees, supply chain, and stakeholder relations under the umbrella brand of "Sustainability". This campaign educates its stakeholders, inspire and engage its employees, enjoin its business partners and align with the local community initiatives. (Ltd., 2016).Few programmes taken up by Shangrila-Eros Hotel, New Delhi are as follows:

- Annual sponsorship to support a child with a severe health condition that is in need of surgery

- Employing graduates from Noida Deaf Society (currently, 8 people from the society have been employed and are working in various areas, from operations to administration, within the hotel)

- Educating and training students from Noida Deaf Society on basic hospitality skills, enabling them to gain employment in the hospitality sector

- Providing financial assistance for at least 2 children from underprivileged families that are suffering from severe health ailments to allow them to undergo life-saving treatments at hospitals.,

- Commitment to the environment by observing Earth Hour at least 4 times a year and participating in a tree planting every year.

- Participation in 'Walk for Life-Stride Against Cancer', which has been organised by CANCER SUPPORT every year for the past eight years to create awareness about cancer, honour those battling cancer and raise funds to fight cancer.

(Ltd., Fast facts:Corporate Social Responsibility, 2016)

- ITC's social outreach programme has been able to generate sustainable livelihood opportunities for around 6 million people through its CSR initiatives. ITC has also achieved the unique global distinction of being carbon positive for nine successive years, water positive for 12 consecutive years and solid waste recycling positive for the last seven years. ITC has, undertaken massive animal husbandry initiatives covering ten lakh animals which form the base for the proposed foray into the dairy business. Renewable energy meets almost $38 \%$ of ITC's total energy requirements. (times, 2014)

- Taj Hotels' corporate sustainability processes run deep and strong, preserving the environment and serving communities wherever in the world its properties are located. Taj Hotels Resorts and Palaces has launched EARTH (Environment Awareness and Renewal at Taj Hotels), a movement minimise the impact of its businesses on the environment. The community of poor and marginalised has been the focus of Indian Hotels' corporate social responsibility programmes, which address an extensive variety of issues. Indian Hotels has motivated other corporate organisations and encouraged them to take on people from marginalised communities. (Ltd, 2015) 
- The Oberoi Group is committed to employing the best environmental and ecological practices in technology, equipment and operational processes. The Group also supports philanthropic activities and is a keen contributor to the conservation of nature and cultural heritage. (Limited, 2016)

- Project Disha a CSR initiative of The Lalit Suri Foundation assist school students and local youth to have access to quality education 'leading to employment' and also equips them to understand the benefits \& opportunities available in today's economic scenario. The area of intervention includes establishment of a library and supplementary teaching, besides providing employment oriented vocational training in the hospitality sector including computer literacy, personality development, spoken English courses \& other skills. (Lalit, 2016)

- Marriott continues its CSR efforts in its hotels to reduce energy and water consumption, waste production, and the carbon footprint; improve its supply chain; expand its number of green hotels; engage guests and associates in sustainable practices to embrace rainforest preservation, water conservation, pushing forward to improve and expand upon its work in all areas of sustainability. (International, 2016)Marriot International has given a new dimension to SERVE in the form of S-Shelter and Food E-Environment R- Readiness for hotel Careers V-Vitality of Children E- Embracing diversity and people with disabilities. (Rajiv Kumar, 2014)

Few key words associated with corporate social responsibility i.e. triple bottom line (TBL), sustainable tourism, global reporting initiatives (GRI), green hotels, carbon footprint, LEAF and LEED etc. are defined in brief:

$>$ Triple-Bottom-Line-Approach: CSR assists the company to achieve a balance of economic, environmental and social imperatives, and address the expectations of shareholders which is generally known as the 'Triple-Bottom-Line-Approach'.

$>$ Global reporting initiatives: It is an international independent standards organization that helps businesses, governments and other organizations understand and communicate their impacts on issues such as climate change, human rights and corruption.

$>$ Carbon footprint: Wikipedia defines carbon footprint as "the total set of greenhouse gas emissions caused by an [individual, event, organisation, and product.

$>$ Green hotel is an environmentally responsible lodging that follows the practices of green living. They make important improvements to its working structure in order to minimize its impact on the environment.

$>$ LEAF: (Lead for Environment \&Awareness Foundation)- "LEAF work for the environment, ensuring sustainable and holistic development with emphasis on human rights, weaker sections of the society to find solutions to the challenges threatening their lives in the field of health, education with the ultimate aim of establishing an aware, responsible and developed society based upon equality, fraternity and social justice".( http://leafkkr.blogspot.in/)

$>$ LEED: (Leadership in Energy and Environmental Design) -"LEED is a voluntary certification program that can be applied to any building type and any building lifecycle phase. It promotes a whole-building approach to sustainability by recognizing performance in key areas." (Link, 2010)

$>$ Sustainable tourism is committed to making a low impact on the environment and local culture, while helping to generate future employment for local people. The sustainable tourism ensures that development is a positive experience for local people; tourism companies; and tourists themselves.

As per UNESCO; "Sustainable tourism is defined as "tourism that respects both local people and the traveller, cultural heritage and the environment". "A sustainable approach to tourism means that 
neither the natural environment nor the socio-cultural fabric of the host communities will be impaired by the arrival of tourists. Sustainability implies that tourism resources and attractions should be utilised in such a way that their subsequent use by future generations is not compromised". (John Fien, 2000)

Maintenance of Sustainable sites, water efficiency, energy and atmosphere, materials and resources, indoor environmental quality, locations and linkages, awareness and education, and innovation in design, must be followed as hospitality dharma.

\section{RESUlT AND SOLUTIONS}

This paper aims to highlight the hotel industry's engagement in sustainable business practices and recommend a framework of action that recognizes the factors and capabilities affecting hotel environmental management practices.

The analysis results are as follows:

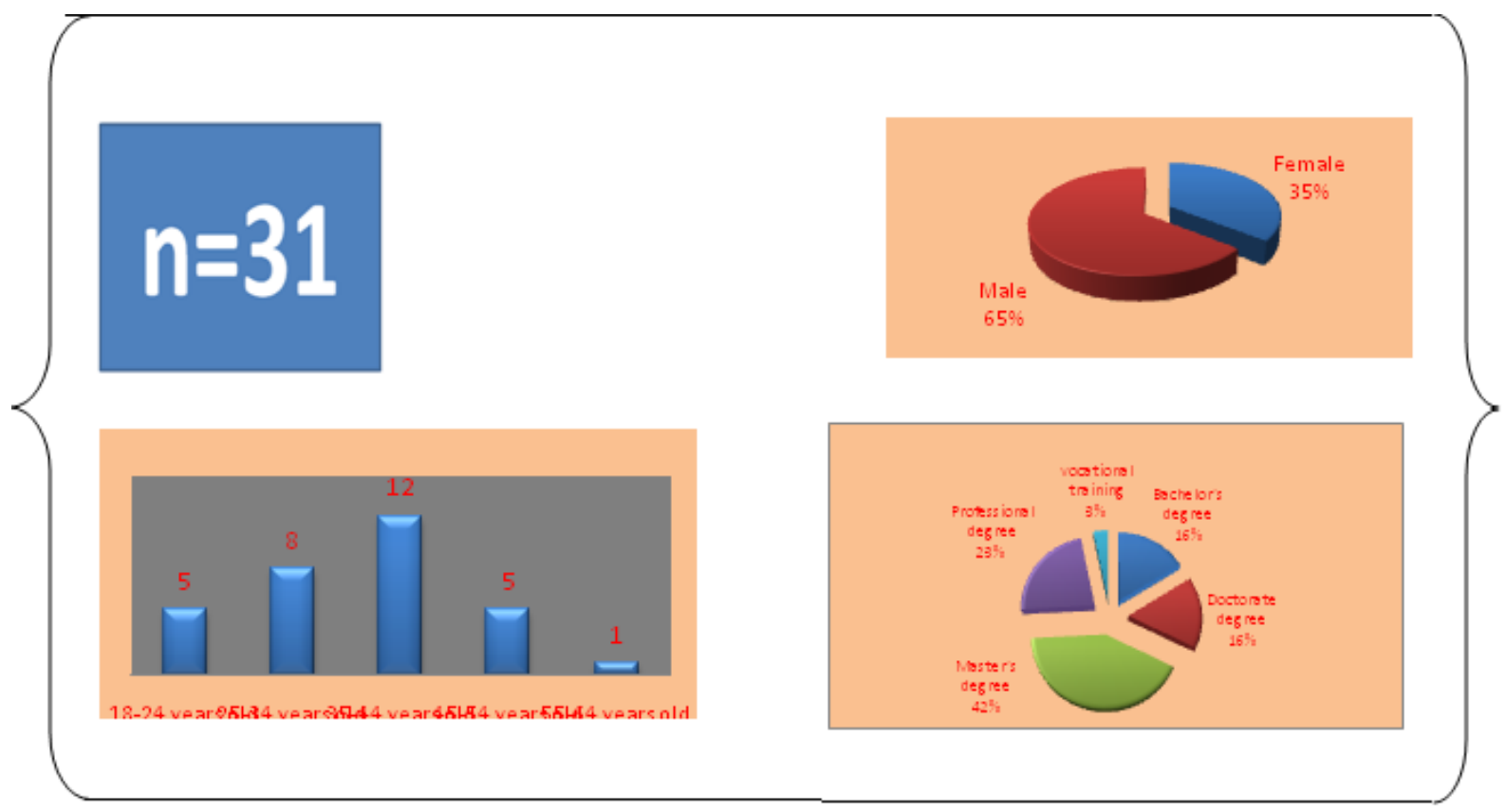

Figure2. Demographical profile of respondents

In total 31 responses were received from hotel employees. 2/3rd respondents of this survey were male. Respondents were spread across 18-64 age groups with maximum in 35-44 age groups. 42\% respondents were holding master degree.

\subsection{Awareness Level of Employees}

Hotel employees were questioned about their awareness regarding the CSR practices followed by hotels. The graphical representation of the test result is represented.

Table1. Awareness level of employees

\begin{tabular}{|l|l|l|}
\hline \multicolumn{1}{|c|}{ Awareness level } & \multicolumn{1}{c|}{ Yes (\%) } & \multicolumn{1}{|c|}{ No (\%) } \\
\hline Significance of sustainability and business practices & $83.9 \%$ & $16.1 \%$ \\
\hline Reflect core values and embrace sustainable practices & $87.1 \%$ & $12.9 \%$ \\
\hline Hotel follows water and energy conservation & $74.2 \%$ & $25.8 \%$ \\
\hline Continue to update and upgrade CSR efforts & $70 \%$ & $30 \%$ \\
\hline Hotels push forward to improve and expand upon its work in all areas of sustainability & $87.1 \%$ & $12.9 \%$ \\
\hline
\end{tabular}

Table no.1 signifies the awareness level of employees regarding the CSR practices followed in their hotels. Significance of sustainability is signified by $83.9 \%$, Reflection of core value by $87 \%$, Water and energy conservation by $74.2 \%$, updating and upgrading CSR efforts by $70 \%$, improving and expanding upon the work is validated by $87.1 \%$ of employees. 


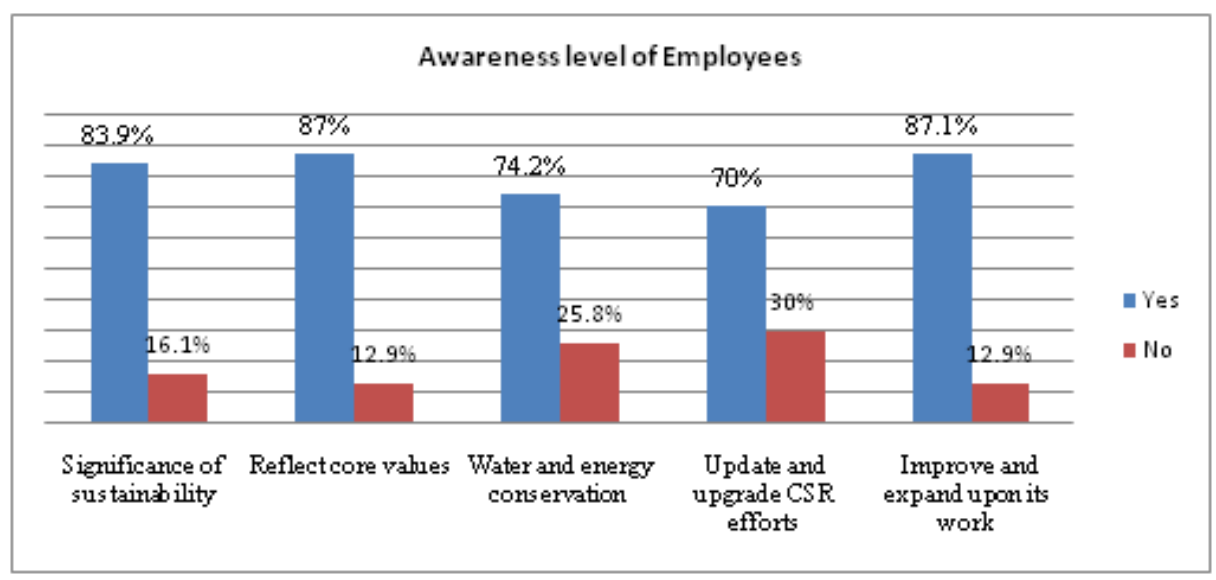

Figure 3: Awareness level of employees

\subsection{Best Practices of Corporate Social Responsibility}

Hotel employees were enquired about the best practices of corporate social responsibility implementation in hotel industry. Their responses were as follows:

Table2. Best practices of corporate social responsibility

\begin{tabular}{|l|l|l|}
\hline Best practices of Corporate Social Responsibility & No. of responses & Percentage \\
\hline Reduce energy, water consumption, waste production, and the carbon footprint & 16 & 51.6 \\
\hline Improve the supply chain & 1 & 3.2 \\
\hline Expand number of green hotels & 3 & 9.7 \\
\hline Engage guests and associates in sustainable practices. & 9 & 29 \\
\hline Triple Bottom Line (TBL) sustainability & 0 & 0 \\
\hline Global Reporting Initiative (GRI) & 1 & 3.2 \\
\hline Other & 1 & 3.2 \\
\hline
\end{tabular}

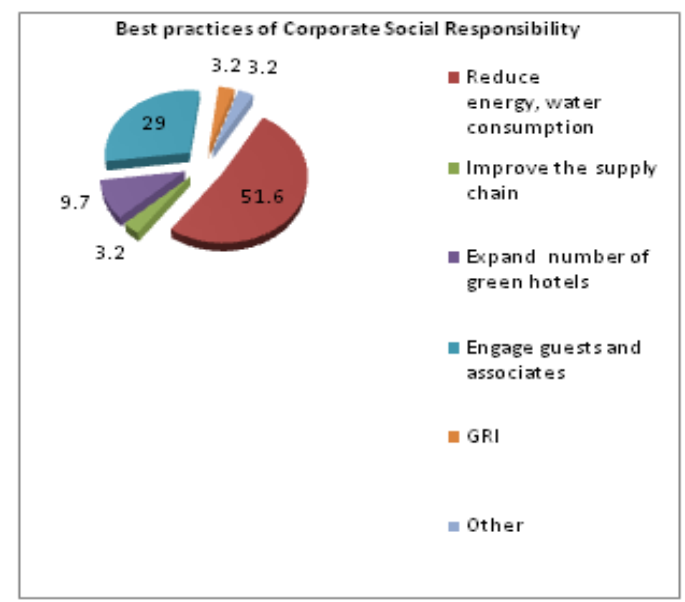

Figure4. Best practices of CSR

According to hotel employees reducing energy, water consumption, waste production, and the carbon footprint received 51.6\%, engaging the guest and associates in sustainable practices received $29 \%$ responses, expanding number of green hotels recorded 9.7\% responses, global reporting initiatives, improving the supply chain and other practices obtained $3.2 \%$ responses.

\subsection{Rating the CSR}

Table3. Rate the effectiveness

\begin{tabular}{|l|l|l|}
\hline \multicolumn{2}{|c|}{ Rate the overall effectiveness of CSR } \\
\hline \multicolumn{1}{|c|}{ Level } & \multicolumn{1}{c|}{ Po. of responses } & \multicolumn{1}{c|}{ Percentage } \\
\hline Poor & 1 & $3.2 \%$ \\
\hline Good & 23 & $74.2 \%$ \\
\hline Very Good & 7 & $22.6 \%$ \\
\hline
\end{tabular}


Sustainable Business Practices and Corporate Social Responsibility in 5- Star Hotels of National Capital Region in India

Table4. Rating the understanding

\begin{tabular}{|l|l|l|}
\hline \multicolumn{2}{|c|}{ Rate the understanding of stakeholder group } \\
\hline \multicolumn{1}{|c|}{ Level } & \multicolumn{1}{|c|}{ No. of responses } & \multicolumn{1}{c|}{ Percentage } \\
\hline Poor & 3 & $9.7 \%$ \\
\hline Good & 22 & $71 \%$ \\
\hline Very Good & 6 & $19.4 \%$ \\
\hline
\end{tabular}

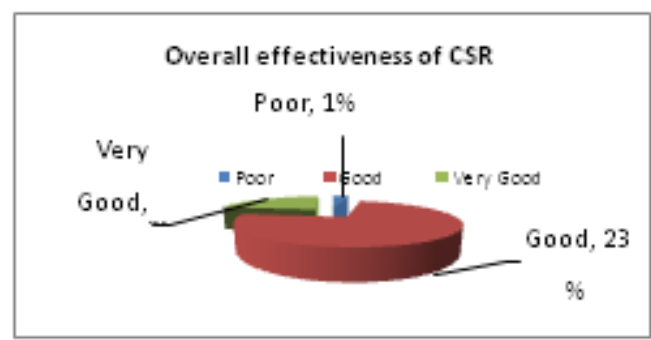

Figure5. Rating the effectiveness

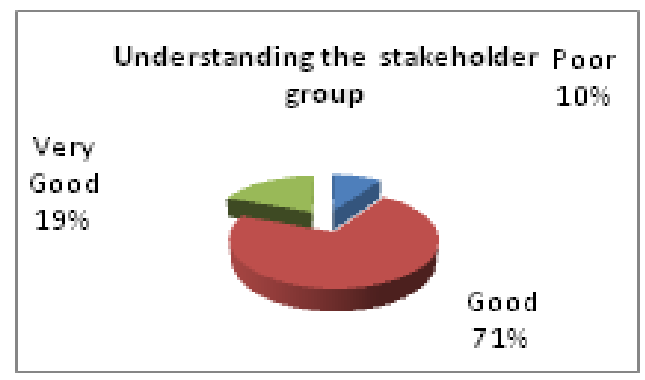

Figure 6: Understanding the stake holder group

Table no. 3 and 4 depicts the rating of CSR on scale of poor, good and very good.

- The overall effectiveness of CSR is rated with good rating by $23 \%$, very good by $7 \%$ and poor by $1 \%$ respondents.

- Understanding the stakeholder group is rated with good rating by $72 \%$, very good by $19 \%$ and poor by $10 \%$ respondents.

\subsection{Knowledge about CSR}

Hotel employees were asked how they get know about company's CSR standards. Their responses were as follows:

Table5. Knowledge about CSR

\begin{tabular}{|l|l|l|}
\hline \multicolumn{1}{|c|}{ Knowledge } & \multicolumn{1}{c|}{ No. of responses } & \multicolumn{1}{c|}{ Percentage } \\
\hline Employee Orientation & 13 & $43.3 \%$ \\
\hline Departmental training & 5 & $16.7 \%$ \\
\hline Company Website & 5 & $16.7 \%$ \\
\hline Annual Report & 7 & $23.3 \%$ \\
\hline
\end{tabular}

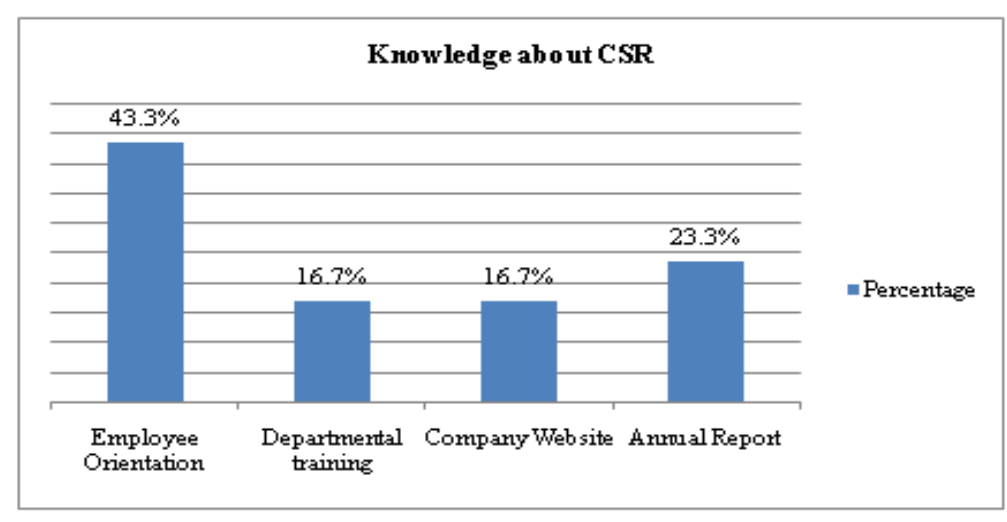

Figure7. Knowledge about CSR 
According to Hotel employees $43 \%$ respondents gained knowledge about CSR through Employee Orientation, where in $23.3 \%$ learnt about it through the annual report, wherein $16.7 \%$ respondents discovered it through departmental training and company web-site.

\subsection{Suggest Additional Sustainability Practices}

Hoteliers were asked to suggest additional sustainability practices that would be useful and desired in the future in lodging operations. Their responses are compiled below:

$>$ Judicial usage of natural resources should be focused while designing the CSR and sustainability projects for any organisation. Hotels must develop the standard business practice for minimum use of papers and encourage guests for linen reuse.

$>$ Hotels should use designs and equipment which consumes less water like low flow taps and shower fittings, energy efficient machines, improvements in design structure i.e. certified green buildings and the food wastage should be prevented and all guest should be oriented towards reuse of linen and reducing the food wastage.

$>$ Sustainability education about lodging operations should be made compulsory, the objective should be to sensitize the employee about the "green" lodging programmes i.e. Leadership in Energy and Environmental Design (L.E.E.D.).

\subsection{Corporate Social Responsibility Efforts}

Hotel employees were asked to suggest Corporate Social Responsibility efforts that they might engage in if they were the manager of a hotel?

Responses received to this question were varied. The hotel employees have particularly laid stress on education for Women. They opinionated that the best way of implementing CSR is to keep a tab on the resources being used for operations so that the strategic planning may be carried out for reduce, reuse, and recycle. They would like to plan philanthropic activities for the lower middle-income group. Hotel employees are willing to minimize the use of papers, use the system for safeguarding our future and would like to encourage guests for reuse of the linen in rooms. They recommend the involvement of all level of employees.

Hoteliers are of the view that Awareness is the key to success. Therefore, the training sessions must be organized for CSR activities. Hotel employees were keen to involve locals into the mainstream operations of the CSR as well as conduct such activities in the neighbourhood to uplift the status of low-income group people by offering them skill development program i.e. Computer literacy, cooking, baking etc. The organizations are willing to partner with local schools to enhance children's learning and organizing trips to the hotel for the children.

Hoteliers believe that donating the unused food to needy may solve the problem of poverty and starving. Clothes, blankets, etc can be donated to charitable organizations. NGOS' must be supported and operated for the development of poor children.

The 3 R's of reducing, reusing \& recycling must be adopted by all the organizations; along with better management of E-waste. Awareness programmes and training sessions must be conducted from time to time.

To be deemed as true corporate citizens, businesses should not only demonstrate CSR during times of difficulty ideally it should be based on measures of adherence.

For effective practices, it must be mandatory to sensitize all stakeholders. The things must improve at ground level; par stock in housekeeping operations must be cut down.

It is necessary to sensitize common people about rainwater harvesting, planting trees, advance use of solar energy and improving the quality of reusable water to make the exercise more effective.

It is summed up with three significant points:

$>$ Implement most of the nature conserving practices in slander working. No resources shall be wasted and go down to drains. 
$>$ Educate other associates i.e. vendors towards the resources conservation. Each one teaches one make everyone literate, financially sound and independent.

$>$ Develop the social sustainability through employing more locals for petty jobs in the organization.

\section{Meeting The OBJECTIVES}

For meeting the objectives of the research study, strategic planning was carried out for collecting and comparing the data.

\subsection{Objective 1}

To explore and compare the CSR practices adopted by 5-star hotels in National Capital Region. To meet this objective, the CSR practices carried out by 5-star hotels in NCR were collected and compared. The resulting analysis represents practice of reducing energy and water consumption, waste production, and reducing the carbon footprint

\subsection{Objective 2}

To analyze the CSR concept from the employee's perspectives and identify the reasons for the 5-star hotels to engage in eco-friendly practices. The employee's perspective is being analyzed by checking their knowledge and awareness level about CSR. It was determined that the hotel employees have gathered knowledge about CSR through employee orientation, departmental training, company website and annual report.

\subsection{Objective 3}

To judge the hotel employee's awareness towards the significance of corporate social responsibility .Through the structured questionnaire, the hotel employee's awareness was being examined about the CSR practices being followed in hotels.

\subsection{Objective 4}

To recommend strategies for further improvement in the adoption of CSR initiatives based on the perspectives of the employees. Recommendations given by hotel employees are compiled and presented below.

\section{FINDINGS}

Corporate social responsibility means different things to different people. In several organizations, CSR is viewed as a charitable exercise, the corporate follow it as a compulsion where in few organizations; it is being taken for the welfare of society. It was found that probably hotels indulge in CSR activities to maintain the star classification criteria.

The research study found that most of the CSR practices followed by the 5-star hotels of NCR were almost similar, with only a few exceptions for some specific projects. Further, the major reason for the hotels to engage in CSR was the economic and social development of community .This also enables the firms in meeting the needs of mandatory CSR activities.

Ideally the businesses participant in CSR should not be viewed lightly, but rather serious consideration must be given to how best CSR should be implemented. An effort is considered to be successful when the awareness can be created amongst associates and guests to inspire them to understand their responsibility towards the sustainability of the environment.

Researcher opines that the environment awareness programs should be designed to educate the masses about environmental commitment. Raising awareness and volunteering in small initiatives i.e. linen and towel re-use policies gives the opportunity to guest to join water and energy conservation efforts. Participation in local clean-up projects may assist the government in keeping the city neat and clean.

Sustainability is the key to our survival in future. The introduction of Environment studies, Value, ethics and CSR subjects as mandatory inclusion in graduation and post graduation level in University education process is bringing the gradual change in thought process of Indian regime. 


\section{RECOMMENDATIONS}

Conclusions emerging from the paper are highlighted and suggestions for future research are discussed.

- To help mitigate the direct and indirect environmental impacts, luxury hotels must invest in conservation initiative for environmental strategy i.e. adopting best practices of biodiversity; luxury hotels must reduce carbon emissions and energy consumption in the hotel must be closely guarded. Core competencies related to the management of carbon emissions, energy, waste, and water must be developed in the hotel as Standard Operating Procedure and the staff members should follow it diligently to safeguard our environment. Standing instructions about protection of nature has to be followed and violators must be punished.

- The hotels must seek feedback from their guest for introducing new CSR practices, as they are the stakeholders of the brands that they endorse. All the employees must be engaged in philanthropy activities periodically to understand the significance of such activities to value its accountability. Awareness level of the employees has to be raised by training and involving them in CSR activities.

- Each one teaches one makes everyone literate. Established business house should financially support the people below poverty level .Hotel's indulgence in programs like skill India program can provide a lot of employment opportunities to uneducated and unskilled locals from the nearby area.

- Organizations should strictly follow the standard operating procedure .Use of biodegradable products and water conservation practices should be made compulsory. Composting of wet waste, creating bio gas, using STP water for gardening and better segregation of waste can boost a very positive change.

- Reducing usage of paper by using the electronic display is an effective method to create awareness. Hotels must insist on print only if necessary.

- Generally CSR activities are erratic due to hectic schedules; it has to be an ongoing process i.e. lowering carbon footprints, , installing energy meters ,reducing food miles , going organic supporting local sustainability, engaging guest for responsible tourism creating awareness among locals, developing medical camps, offering mineral water in glass bottles to minimize the use of plastic, reducing use of items which are difficult to recycle.

- Hotels must support local handicrafts and culture, as the artisans and artist keep the culture alive as it offers the employment to local people. Contributions to school, better recording of data's.

- Considering the time bomb of population in India, organizing awareness on deadly diseases like tuberculosis, cancer, and heart diseases holds more significance as the dissemination of knowledge creates understanding among general population. Holding the community meetings, conducting health education through flip charts and video film can benefit the society in general. These activities mobilize assistance to the poor patients and their families from a number of agencies.

- Depletion in the level of water, growing scarcity of food resources due to the time bomb of the overpopulation makes India a vulnerable nation. The entire nation must engage in saving the climate and environment. Thanks to the effort of all the corporate houses that CSR has moved from the periphery to become a majority business issue. Real change can already be seen in hospitality business practices and their changing behaviour. We as citizens of India should continue to push for more progress of India. It is a continuous process to think over for every citizen......

\section{FUTURE RESEARCH DIRECTIONS}

In future, the research may be carried out in additional hotels, as the five hotels of NCR does not represent the CSR practices followed in all the hotels of National Capital Region. 
"Corporate social responsibility is a hard-edged business decision. Not because it is a nice thing to do or because people are forcing us to do it... because it is good for our business" Niall Fitzerald, Former CEO, Unilever

\section{REFERENCES}

[1] Corporate Social Responsibility: Meeting changing expectations, p. 3.

[2] D.Crowther. (2008). Culture and Corporate Governance. Social Responsibility. Research Network.

[3] GOI, M. (2014, December). HRACC guidelines for hotels. New delhi, India.

[4] Henriques, A. (2003, May 26). Ten things you always wanted to know about CSR (but were afraid to ask); Part One: A brief history of corporate social responsibility (CSR),' Ethical Corporation Magazine,. Retrieved from http://www.ethicalcorp.com/conte

[5] International, M. (2016). Corporate Responsibility. Retrieved from http://www.marriott.com: http://www.marriott.com/corporate-social-responsibility/corporate-responsibility.mi

[6] John Fien, M. C. (2000). Multi stakeholder working group on Tourism. UNESCO.

[7] Lalit, T. (2016). The Lalit offer-corporate social responsibility. Retrieved from http://www.thelalit.com/: http://www.thelalit.com/aboutus-en.html\#item5

[8] Limited, T. O. (2016). The Oberoi group. Retrieved from http://www.oberoihotels.com/about-us/profile. aspx: http://www.oberoihotels.com/about-us/profile.aspx

[9] Link, M. (2010, October 20). Retrieved from https://docs.google.com/: https://docs.google.com/document /d /1g01BTJtqKGIMNyP3BDKZBQ5SxHEOHy9iubnAqiyCc14/edit

[10] Ltd, T. S. (2015, November). Interviews and Stories. Retrieved from http://www.tata.com: http://www.tata.com/company/articlesindex/indian-hotels

[11] Ltd., S.-L. I. (2016). Retrieved from http://www.shangri-la.com/: http://www.shangri-la.com/corporate /about-us/ corporate-social-responsibility/sustainability)

[12] Ltd., S.-L. I. (2016). Fast facts:Corporate Social Responsibility. Retrieved November 5, 2016, from http://www.shangri-la.com/newdelhi/shangrila/: http://www.shangri-la.com/newdelhi/erosshangrila/pressroom/fast-facts/corporate-social-responsibility/

[13] Lymn, C. (2009, october). Corporate Social Responsibility in the Hospitality Industry. Flagstaff, AZ, Norhen Arizona.

[14] Qeed, M. A. (2015). The Relationship between Corporate Social The Relationship between Corporate SocialThe Relationship between Corporate Social The Relationship between Corporate Social The Relationship between Corporate Social The Relationship between Corporate Social The . International Business Research, Vol. 8, No. 1; 2015.

[15] Rajiv Kumar, S. S. (2014). Corporate Social Responsibility: A Study on Hospitality Industry. Asian Journal of Multidisciplinary Studies, Volume 2,Issue 4.

[16] Singh, D. (2015, June 5). Five-star hotels go green: Government campaign convinces Delhi's luxury hotels to stop wasting water and electricity . Retrieved April 29, 2016, from http://www.dailymail.co.uk/: http://www.dailymail.co.uk/indiahome/indianews/article-3112975/Five-star-frugality-Delhi-s-luxuryhotels-crack-power-electricity-wastage-government-campaign.html\#ixzz47J2ctxvh

[17] times, E. (2014, December 5). Retrieved from (http://economictimes.indiatimes.com/: (http://economict imes.indiatimes.com/articleshow/45372587.cms?utm_source=contentofinterest\&utm_medium=text\&utm_ campaign $=$ cppst

Citation: Dr. Rekha Maitra. "Sustainable Business Practices and Corporate Social Responsibility in 5- Star Hotels of National Capital Region in India" International Journal of Research in Tourism and Hospitality (IJRTH), vol 4, no. 1, 2018, pp. 45-56. doi:http://dx.doi.org/10.20431/2455-0043.0401006.

Copyright: () 2018 Authors. This is an open-access article distributed under the terms of the Creative Commons Attribution License, which permits unrestricted use, distribution, and reproduction in any medium, provided the original author and source are credited. 